\title{
A EXPRESSÃO DA AFETIVIDADE NA EDUCAÇÃO INFANTIL: CONCEPÇÕES DE ALGUMAS DOCENTES
}

BORBA, Valdinéa Rodrigues de Souza ${ }^{1}$

\begin{abstract}
RESUMO: Este trabalho identifica e analisa o tema afetividade na Educação Infantil. Parte do pressuposto de que a interação social é fator fundante dos processos psicológicos superiores e que estes se constituem da indissociabilidade entre afeto e cognição. Neste sentido, Vygotsky e Wallon trazem contribuições importantes para fundamentar essa relação. A pesquisa qualitativa norteia esta investigação, por meio da observação participante realizada com 60 docentes de uma rede municipal de Educação Infantil. Como procedimentos de coleta de dados foram utilizados questionários para identificar as concepções das docentes sobre o termo afetividade e grupos focais para suscitar reflexões acerca do tema. Relacionando as concepções e reflexões sobre práticas pedagógicas discutidas, foi possível constatar uma diversidade de enfoques sobre o tema: seu significado positivo (amorosidade), a questão dos limites, das situações de conflitos e do ensino conteudista. Estas diferentes concepções contribuem para a discussão sobre o valor que a afetividade representa na práxis docente. Conclui-se que esta questão é vista como de suma importância nesta etapa da constituição da criança e necessita fazer parte de forma significativa nos programas de formação inicial e continuada dos profissionais da Educação.
\end{abstract}

Palavras-chave: Afetividade. Educação Infantil. Psicologia histórico-cultural.

SUMMARY: This work identifies and analyses affective aspects present in Children Education. From this presuppose, the social interaction is an essential factor of superior psychological processes. Vygotsky and Wallon bring important contribution to substantiate this relationship. The ethnographic poll directs this investigation, by the observation included performed by 60 teachers from a municipal network of Children Education. As procedures of data assessment, questionnaires were used to identify the teachers' conception and reflections about pedagogical practices discussed, it was possible to ascertain a diversity of focuses about this theme: its positive result (amorosity), the limit subject, the conflict situation and the content teaching. These different conceptions contribute with the discussion about the value the affection represents in scholastic practices. It has been deduced that this subject is seen as a very important one in this step of children constitution and needs to take part in initial and continual program of teaching experts in a significant way.

Keywords: Affection. Children Education. Historical-cultural Psychology.

\section{INTRODUÇÃO}

O presente artigo resulta de um recorte da pesquisa $A$ afetividade no discurso das professoras de Educação Infantil e apresenta, como, identificar e analisar as concepções de 60 docentes da Educação Infantil sobre a afetividade.

O referencial teórico que fundamenta a concepção de afetividade circunscreve a abordagem da psicologia histórico-cultural, que considera as interações sociais fundamentais na formação dos processos psicológicos superiores, que são constituídos através da alternância entre razão e emoção, ou seja, cognição e afeto.

$1 \quad$ Mestre em Educação. Prof. ${ }^{a}$ Pedagogia na FE/FFCL. E-mail: valdinea@feituverava.com.br 
Advoga que a constituição do sujeito ocorre dentro de uma cultura concreta. Assim, as questões relacionadas aos processos afetivos também representam papéis importantes e não podem ser deixadas de lado. Para tanto, buscam-se aportes nos estudos de Wallon e Vygotsky, que trazem contribuições importantes para fundamentar a relação entre os processos cognitivos e afetivos, em especial, quando discorrem sobre as etapas de evolução da criança, suas relações com o meio sócio-cultural e o papel da linguagem neste desenvolvimento.

\section{COGNIÇÃO, AFETO E INTERAÇÕES SOCIAIS}

O médico, psicólogo e filósofo francês Wallon (1879-1962) dedicou grande parte de sua vida ao estudo das emoções e da afetividade. Assim, fundamentou a sua pesquisa sobre a psicogênese da pessoa completa, considerada em seus aspectos afetivo, cognitivo e motor. Estudando a afetividade e as emoções no decorrer do desenvolvimento, conseguiu identificar as primeiras manifestações afetivas do ser humano e suas principais características, assim como suas múltiplas relações com outras atividades psíquicas. Concebeu a afetividade como fator fundamental na constituição do sujeito e como instrumento de sobrevivência do ser humano, pois corresponde à primeira manifestação do psiquismo.

De acordo com seus estudos, quando recém-nascido, o ser humano utiliza a emoção para comunicar-se com o mundo. Dessa forma, antes mesmo da aquisição da linguagem, o bebê, através de movimentos de expressão, primeiramente fisiológicos, estabelece relação com a mãe ou outra pessoa que dele cuida.

Corroborando este pensamento, pesquisas sócio-genéticas e antropológicas apontam que, desde os primórdios, a expressão das emoções foi extremamente importante para a evolução do homem enquanto pessoa social. De acordo com estes estudos, a emoção possibilitou ao homem a formação de grupos, facilitada por sua capacidade de despertar a cumplicidade de interesses e o espírito de colaboração entre seus pares.

Para Wallon (1979), a personalidade é constituída por duas funções básicas: afetividade (que está vinculada às sensibilidades internas e orientada para o mundo social, para a construção da pessoa) e a inteligência (vinculada às sensibilidades externas e orientada para o mundo físico, para a construção do objeto).

Tanto Vygotsky (2000) quanto Wallon afirmam que não se pode separar afetividade e cognição. Wallon (1978) destaca a alternância existente entre as funções razão (cognitiva) e emoção (afetividade), apresentadas no decorrer do desenvolvimento da pessoa. A razão e a emoção estão imbricadas, ou seja, uma não acontece sem a outra, mas sempre uma se sobrepõe, predominando.

Vygotsky (2003) advoga que o pensamento tem sua origem na esfera da motivação, a qual inclui interesses, necessidades, impulsos, afeto, emoção e inclinações.

No decorrer do desenvolvimento do indivíduo, suas necessidades afetivas vão se tornando 
cognitivas. Vale destacar que, segundo o autor supracitado, a integração entre afetividade e inteligência permite à criança atingir níveis de evolução superiores.

Desta forma, pode-se afirmar, com segurança, que emoção e inteligência se completam mutuamente. Assim sendo, o predomínio exacerbado, durante um longo período, de alguma das duas, pode ser prejudicial ao sujeito, no sentido de provocar um desequilíbrio em seu desenvolvimento.

Fortalecendo este pensamento, Oliveira (1995) afirma que o indivíduo já nasce portador de funções psicológicas elementares e que estas lhes possibilitam construir funções psicológicas superiores. De acordo com a autora, este processo acontece nos espaços interativos.

Góes (1995) também defende esta tese, ao explicar que, para Vygotsky, a constituição do conhecimento dá-se através da mediação, da relação sujeito-sujeito-objeto. Afirma que as características especificamente humanas não estão presentes no indivíduo desde seu nascimento e tampouco apareceram somente devido às influências do meio exterior. De acordo com Vygotsky (1998), elas são produtos da interação dialética do homem e seu meio sócio-cultural. Argumenta, ainda, que o homem transforma a si mesmo ao transformar o meio ambiente, buscando atender às suas necessidades primárias.

Assim, a aprendizagem, na perspectiva da psicologia histórico-cultural, envolve sempre a construção do eu e do outro, entrelaçada à construção do conhecimento. Em outras palavras, a criança constitui seu conhecimento, inserida num grupo, com ajuda do adulto e de outras crianças. Isto porque as experiências vivenciadas com outras pessoas é que vão determinar a qualidade do objeto internalizado. Constituindo a história de vida de cada um, estas experiências acumuladas possibilitarão a construção do próprio “eu”, ou seja, a ressignificação individual do conhecimento internalizado.

Para Galvão (1995), este processo de internalização do material cultural define os limites e possibilidades da construção pessoal, permitindo, assim, a constituição do ser autenticamente humano. Em outras palavras, na ausência do outro, o homem não se constrói.

\section{A PESQUISA}

A pesquisa utilizou os pressupostos da investigação qualitativa visando a trabalhar com aspectos mais profundos das relações e processos de fenômenos (MINAYO, 2001); e estudou as concepções e reflexões sobre afetividade de 60 docentes da Educação Infantil, que integravam o corpo docente de uma Escola Municipal de Educação Infantil (EMEI) e de 7 Creches a ela vinculadas, no interior do Estado de São Paulo. Os dados foram coletados de agosto de 2003 a julho de 2004.

Iniciou-se, buscando compreender como as docentes vêem a questão da afetividade na relação educador-educando. Os instrumentos selecionados foram: aplicação de questionário 
individual e escrito e discussão em grupos focais ("O que você entende por afetividade?").

\section{OS RESULTADOS}

Após análise dos conteúdos das respostas e das unidades de significado delas decorrentes, verificou-se que 40 das 60 docentes investigadas associam o termo afetividade às palavras carinho, querer bem ao outro, amizade, amor, afeto, entre outros, indicando a compreensão da afetividade como sinônimo ou expressão de sentimentos positivos.

O predomínio desta relação, expressa nos depoimentos das docentes da Educação Infantil, pode ser interpretado como conseqüência do constante atendimento a crianças dessa faixa etária (4-6 anos) que se comunicam pela expressividade corporal e aceitam bem os toques físicos e afagos dos adultos e de outras crianças. O próprio histórico da Educação Infantil, retratado por ocasião dos Jardins de Infância, pode ter influenciado respostas com esse significado. Não obstante, as jardineiras (docentes) cuidavam das crianças pequenas como se fossem plantinhas que necessitavam ser "regadas" diariamente com carinho e amor, desde a mais tenra idade (BASTOS, 2001).

Cabe ressaltar que todos estes fatores podem ser reforçados pela predominância de mulheres como profissionais da Educação Infantil, que se reportam ao instinto maternal para o exercício docente.

Verificou-se também que a maioria das docentes fundamenta e justifica seus argumentos no senso comum.

Uma parte das docentes (14 delas) acredita que a afetividade se manifesta em relações escolares, em especial nas interações entre educador-educando, bem como em relações ocorridas no âmbito familiar e social. Destacando a afetividade como inerente às relações humanas, aproximam-se de uma compreensão mais complexa e mais próxima do que acontece na vida real. Por não explicitarem ou estabelecerem relações com alguma teoria, suas concepções parecem partir de suas observações e vivências no fazer pedagógico.

Cinco docentes atribuíram à afetividade o papel de facilitadora da aprendizagem, entendida como pré-condição para a apropriação de novas aprendizagens pela criança, sendo o educador um mediador neste processo; parecem muito conscientes da necessidade de buscar seu papel como educadoras, frente à concepção de Educação Infantil que retrata o educando como um sujeito em fase de formação e com características próprias (BRASIL, 1999), parecem saber que, assim sendo, a criança necessita de educação e cuidados que favoreçam o seu desenvolvimento não apenas intelectual e também, a sua constituição como pessoa completa.

$\mathrm{Na}$ discussão realizada nos grupos focais, 13 docentes destacaram os efeitos que a prática afetiva pode acarretar aos educandos. Afirmaram que ela norteia o desenvolvimento da criança, especialmente de sua personalidade, auxiliando na formação de seu caráter. Para estas , a afetividade tem o poder de ampliar as interações sociais, solidificar laços de amizade e promover qualidade nos relacionamentos. Afirmaram que a afetividade é capaz de resgatar e/ou 
fortalecer a auto-estima do indivíduo, ajudando-o na superação de obstáculos e promoção de sucesso. Aqui, as concepções das docentes encontram substrato teórico nos estudos de Vygotsky e Wallon, que destacam o papel da afetividade nas relações sociais e destas no desenvolvimento do ser humano.

Verificou-se, também, nas discussões coletivizadas nos grupos focais, que 25 docentes entenderam como explicitações de afetividade, a postura assumida e as atitudes do educador durante o exercício de suas funções. Para elas, o interesse, a atenção, a compreensão, o envolvimento, o respeito do educador pelos educandos e seus problemas, bem como o fato de dar voz a esses pequenos sujeitos (ouvindo-os com atenção), de se expressar com palavras adequadas, olhares e gestos carinhosos, são atitudes importantes que contribuem para a formação das crianças, marcando-as positivamente.

Sob um enfoque mais realista e menos utópico, apenas quatro docentes abordaram que a afetividade seria, também, a expressão de conflitos, discordâncias e desafetos entre docente e educandos e entre as próprias crianças. Para estas docentes, a afetividade norteia as relações humanas, tanto as brigas e confusões, como as expressões de agrado e concordância.

Vale destacar que, apenas em uma resposta, apareceu a questão dos limites infantis e da necessidade de demarcá-los com as crianças, até mesmo como uma expressão de afetividade.

Faz-se oportuno lembrar que, no cotidiano de qualquer instituição escolar, deflagramse muitas expressões de afetividade, como momentos de carinho, afeição, solidariedade, mas também situações de embate, desentendimento entre os próprios educandos, entre educador e educando.

Diante do pequeno número de docentes que assumiram, sem constrangimento ou pieguice, esta compreensão mais dialética e complexa do termo afetividade, a questão que se coloca, agora, remete à reflexão sobre o que poderia ter levado a maioria das docentes a um entendimento limitado e restrito do termo, fazendo referências, apenas, a aspectos menos polêmicos da afetividade. Algumas possibilidades: estas docentes podem estar apresentando dificuldades para aceitar e lidar com os conflitos, tão comuns nas relações humanas; ou então, em suas repostas, preferiram abordar somente os aspectos considerados por elas, nas interações sociais, como "positivos" e, por assim dizer, "politicamente corretos" no crivo do senso comum.

O que precisa ficar claro para todos os profissionais da Educação é que, se as interações próprias da sala de aula são carregadas de afetividade, seguramente, esta carga afetiva, seja ela positiva ou negativa, vai exercer influência na aprendizagem. Dessa forma, não se justifica tentar camuflar ou ignorar os conflitos, pois o que importa nas interações escolares é como e em que medida o docente "afeta" os seus educandos; o quanto estes se sentem queridos, protegidos, importantes ou não para o seu professor. E isso não significa "passar a mão sobre a cabeça" da criança; refere-se a não sentir-se ignorada pelo professor. Divergências de opiniões, discussões e brigas entre crianças pequenas são normais e devem ser encaradas e, se necessário, resolvidas com a mediação do adulto, e, neste caso, o estabelecimento de limites e regras é fundamental. 
Como mostra Wallon (1979), desde o nascimento, a criança vivencia diversas fases de desenvolvimento onde predominam ora a afetividade, ora a cognição. Para este autor, a criança dos três aos cinco anos de idade vivencia a fase personalista, onde há predominância da afetividade. De acordo com seus estudos, nessa fase, a criança vai constituindo seu Eu, sua subjetividade, sua personalidade; e este processo de individuação (distinção entre o Eu e o Outro) acontece através de atividades de oposição ao outro e, ao mesmo tempo, de sedução e de imitação, tão comuns nas relações infantis. Além de comuns, são necessárias para a formação da personalidade da criança.

Observou-se, também, a resposta de uma única docente que relacionou a afetividade às expressões físicas das emoções e com suas reações orgânicas, tais como aceleração do batimento cardíaco, brilho nos olhos, sorriso e vozes alegres.

Corroborando este pensamento, Galvão (1995) afirma que a emoção, presente nos conflitos das relações sociais, faz parte do processo de constituição do sujeito. E complementa que, sabendo-se que a emoção precisa de um espectador, vale refletir sobre a postura do adulto frente às manifestações de crises emocionais das crianças, considerando que "na ausência da platéia as crises emocionais tendem a perder sua força”. (ibidem, p.64).

Vale destacar que as emoções modificam-se e evoluem no contato social, sendo que quem dá sentido às manifestações emocionais da criança é o outro.

\section{CONSIDERAÇÕES FINAIS}

Considerando-se a fundamental importância da afetividade deflagrada pelos resultados obtidos na pesquisa de campo e revisão de literatura, conclui-se que há uma forte preocupação destas docentes em "afetar" positivamente seus educandos. Assim sendo, oportunizam momentos e espaços adequados ao estabelecimento de interações sociais capazes de promover o desenvolvimento do sujeito em suas dimensões cognitiva, afetiva, motora e social.

Neste contexto, reafirma-se que, para Wallon (1975), são os desejos, os motivos, e as necessidades que dirigem o interesse da criança para o conhecimento e conquista do mundo exterior. Portanto, a afetividade desempenha um papel fundamental na constituição e funcionamento da inteligência, pois, determina os interesses e necessidades individuais, o que possibilitará avanços progressivos no campo intelectual.

Buscando fundamentos nos estudos feitos por Vygotsky e Wallon, pode-se afirmar que a afetividade é vital em todos os seres humanos, de todas as idades, mas, especialmente, no desenvolvimento infantil. De acordo com estes teóricos, a afetividade está sempre presente nas experiências empíricas vividas pelos seres humanos, no relacionamento com o "outro social", por toda a sua vida, desde seu nascimento. Dessa forma, quando a criança entra na escola, torna-se ainda mais evidente o papel da afetividade na relação educador-educando.

Confirma-se, também, neste estudo que o educador, dentro da sala de aula, é o principal mediador do processo ensino-aprendizagem, ocupando uma função ímpar e privilegiada no 
desenvolvimento da criança. $\mathrm{O}$ docente pode contribuir para o sucesso ou o fracasso de seus educandos na escola. Como mediador, ele pode promover o estabelecimento de vínculos afetivos muito fortes e saudáveis com e entre os educandos. Sabe-se que, através de sua dedicação e comprometimento profissional, das sondagens dos conhecimentos prévios da turma, das intervenções adequadas e pertinentes, das correções que faz, dos elogios, dos incentivos que dá, da ajuda na resolução de problemas, o docente pode ensinar muito a seus educandos. Pode também, conquistar a admiração, a simpatia e o respeito de seus educandos e o apoio de seus familiares através de suas atitudes de respeito à diversidade e limitações específicas de cada ser humano, na disseminação de valores éticos e de solidariedade e de valorização dos diferentes saberes e culturas.

Dessa forma, na teoria e na prática, constata-se que as interações entre as docentes e discentes não se limitam apenas aos aspectos cognitivos, pois são impregnadas de afetividade. E, sabendo-se que a afetividade orienta o sucesso ou fracasso das relações, pode e deve se tornar aliada de todos os educadores conscientes de seu papel.

Portanto, é salutar que, articuladas às políticas públicas sociais de apoio à criança, as instituições de Educação Infantil se constituam num espaço onde as formas de expressão da criança de 0 a 6 anos, dentre elas a linguagem afetiva, verbal, corporal e o brincar ocupem lugar de destaque.

Finalizando, todas as instituições escolares, e neste caso específico, as de Educação Infantil, devem ser sempre locus de investigação e estudos por parte do educador, de sua própria prática pedagógica. Devem ser, também, um espaço dinâmico, vivo, alegre e saudável, no qual as crianças se desenvolvam integralmente, alcançando o pleno desenvolvimento de suas potencialidades e capacidades afetivas, emocionais, motoras, cognitivas, estéticas, éticas, de relação interpessoal e inserção social. Primando pela qualidade da educação e cuidados oferecidos, estas instituições de Educação Infantil propiciarão interações sociais pautadas na afetividade, contribuindo assim, para a formação de crianças saudáveis, inteligentes, participativas, afetivas e muito, muito felizes!.

\section{REFERÊNCIAS}

BASTOS, M.H.C. Jardim de crianças: o pioneirismo do Dr. Menezes Vieira (1875-1887). In: MONARCHA, C. (org.). Educação da infância brasileira: 1875-1983. Campinas: Autores Associados, 2001, p. 31-80.

BORBA, V.R. de S. A afetividade no discurso das professoras de Educação Infantil. Dissertação (Mestrado). Centro Universitário Moura Lacerda. Ribeirão Preto, 2005.

BRASIL. MEC. Lei de Diretrizes e Bases da Educação Nacional n. 9.394/96. Brasília: MEC, 1996.

BRASIL. Ministério da Educação e do Desporto. Secretaria de Educação Fundamental. 
Referencial curricular nacional para a educação infantil. Brasília, DF: MEC/SEF, 1998.

. Resolução CEB 1/99. Diretrizes Curriculares Nacionais para a Educação Infantil. Diário Oficial da União, Brasília, 13/04/1999, seção 1.

GALVÃO, I. Henri Wallon: uma concepção dialética do desenvolvimento infantil. Petrópolis, RJ: Vozes, 1995.

O papel das emoções e da motricidade expressiva nas interações sociais no meio escolar. São Paulo, SP: USP, 1998. Tese (Doutorado em Educação) - Universidade de São Paulo, 1998.

GÓES, M.C.R. A construção de conhecimentos: examinando o papel do outro nos processos de significação. Temas de Psicologia, n.2, 1995, p. 23-29.

MINAYO, M.C.S. (Org). Pesquisa Social: teoria, método e criatividade. Petrópolis / Rio de Janeiro: Vozes, 2001.

OLIVEIRA, Z.M.R. Interações sociais e desenvolvimento: a perspectiva sócio histórica. In: Caderno Cedes, n.35, 1995, p. 51-64.

VYGOTSKY, L.S. A formação social da mente. São Paulo: Martins Fontes, 1984.

. Pensamento e linguagem. São Paulo: Martins Fontes, 1993.

. Teoria e método em Psicologia. São Paulo: Martins Fontes, 1996.

O desenvolvimento psicológico na infância. São Paulo: Martins Fontes, 1998.

A construção do pensamento e da linguagem. São Paulo: Martins Fontes, 2000.

Psicologia Pedagógica. Porto Alegre: Artmed, 2003.

WALLON, H. As origens do caráter na criança. São Paulo: Difusão Européia do livro, 1971.

. Psicologia e educação da infância. Lisboa: Estampa, 1975.

A evolução psicológica da criança. Lisboa: Portugal: Edições 70, 1978.

1979.

Do acto ao pensamento: ensaio de psicologia comparada. Lisboa/Portugal: Moraes, 